\title{
PANAMÁ Y EL RÉGIMEN DE NEUTRALIDAD
}

\section{PANAMA AND THE SYSTEM OF NEUTRALITY}

\author{
AUTOR \\ Julio Yao \\ Presidente del Servicio Paz y Justicia en Panamá (Serpaj-Panamá).Catedrático de Relaciones \\ Internacionales y Derecho Internacional. \\ julioyao@gmail.com
}

\section{RESUMEN}

Panamá es neutral ante cualquier conflicto bélico. La reserva Nunn fue creada para facilitar acuerdos entre EEUU y Panamá en cuanto a esta neutralidad. El artículo V invalida esta reserva. Se crea el Protocolo al Tratado de Neutralidad. Estos dos países son los encargados de que este tratado se cumpla.

\section{PALABRAS CLAVE}

Reserva Nunn - Tratado Neutralidad - Panamá - EEUU

\section{ABSTRACT}

Panama is neutral in any conflict. Nunn reserve was created to facilitate US-Panama agreements concerning this neutrality. Article $V$ does not confirm this reservation. Creation of the Protocol to the Treaty of Neutrality. These two countries are responsible for this treaty is enforced.

\section{KEY WORDS}

Reserve Nunn - Treaty Neutrality - Panama - USA 


\section{ÍNDICE}

1. Neutralidad y desmilitarización extranjera

2. Inadmisibilidad de la Reserva Nunn

3. Protocolo de adhesión al "Tratado de Neutralidad"

4. Presencia militar extranjera y "Tratado de Neutralidad"

\section{Neutralidad y desmilitarización extranjera}

La desmilitarización extranjera constituye un principio inherente a todo régimen neutral y es indispensable porque el propósito de la neutralidad no es sólo evitar un ataque al Canal, sino asegurar primordialmente la libertad de tránsito, la cual se vería amenazada si una gran potencia ocupa las riberas de la vía interoceánica.

Según el Artículo II del Tratado Concerniente a la Neutralidad Permanente y al Funcionamiento del Canal de Panamá (Tratado de Neutralidad). Panamá declara la neutralidad del Canal para que, tanto en tiempo de paz como en tiempo de guerra, éste permanezca seguro y abierto para el tránsito pacífico de las naves de todas las naciones $[\ldots .$. ] y para que el canal y consecuentemente el Istmo de Panamá, no sea objetivo de represalias en ningún conflicto bélico. Lo anterior quedará sujeto: "[...] (d) Al cumplimiento de otras condiciones y restricciones establecidas en este tratado".

Entre las condiciones está lo dispuesto en el Artículo V del "Tratado de Neutralidad":

"Después de la terminación del Tratado del Canal de Panamá, sólo la República de Panamá manejará el Canal y mantendrá fuerzas 
militares, sitios de defensa e instalaciones militares dentro de su territorio nacional".

\section{Inadmisibilidad de la Reserva Nunn}

Se ha dicho que la presencia militar extranjera pudiera ser acordada entre Panamá y los Estados Unidos en virtud de la Reserva Nunn. Nosotros negamos esa posibilidad. Veamos qué dispone la Reserva Nunn:

"En este tratado no hay nada que impida que Panamá y Estados Unidos, de acuerdo con sus respectivos procesos constitucionales, concluyan un acuerdo o arreglo entre los dos países para facilitar el desarrollo, en cualquier momento después del 31 de diciembre de 1999, de sus responsabilidades y mantener el régimen de neutralidad que se establece en el tratado, incluso acuerdos o arreglos para apostar tropas norteamericanas o para mantener los sitios de defensa después de dicha fecha en la República de Panamá cuando Panamá y EEUU lo estimen necesario o adecuado".

Lo único que dice la Reserva Nunn es que nada en el Tratado se interpretará como un impedimento para un acuerdo. La reserva Nunn no establece obligación alguna de negociar. Suponiendo, sin conceder, que la Reserva Nunn poseyera algún valor Jurídico y ambos Estados (Panamá y EEUU) llegaran a un acuerdo, el propósito de la presencia militar estadounidense sólo sería el de "facilitar el desarrollo, en cualquier momento después del 31 de diciembre de 1999, de sus responsabilidades y mantener el régimen de neutralidad". Por lo tanto, las fuerzas militares de los EEUU no podrían ser utilizadas para propósito distinto. Pero el mantenimiento de la neutralidad tampoco requiere la presencia militar de los EEUU. Ahora bien, ¿es cierto 
que nada en este Tratado de Neutralidad impide un acuerdo entre Panamá y los EEUU?

No es cierto, porque el Artículo V del "Tratado de Neutralidad" estipula claramente que "sólo la República de Panamá manejará el Canal y mantendrá sitios de defensa e instalaciones militares dentro de su territorio nacional" después del 31 de diciembre de 1999 y el mismo no admite interpretación distinta. El régimen de neutralidad, que constituye el único objeto y fin del "Trtado de Neutralidad", hace imposible la presencia militar extranjera después del 31 de diciembre de 1999 y, por ende, la Reserva Nunn es de imposible cumplimiento. La Reserva Nunn constituye un intento de evadir el cumplimiento del Artículo V del "Tratado de Neutralidad", la desmilitarización del Canal, y su propósito; por lo tanto, su objetivo es erosionar una condición sine qua non, una condición esencial, de la neutralidad permanente. La inadmisibilidad de reservas como la Reserva Nunn es prevista en el Artículo 19 de la Convención de Viena sobre el Derecho de los Tratados (U.N. Doc. A / CONF. 39/27, Viena 23 de mayo de 1969; 1155 U.N.T.S. 331, vigente desde junio 27 de 1980):

"Un estado podrá formular una reserva en el momento de firmar, ratificar, aceptar o aprobar un tratado o adherirse al mismo, a menos: [...] que la reserva sea incompatible con el objeto y el fin del tratado".

La Reserva Nunn, por ser incompatible con el objeto central y el fin del "Tratado de Neutralidad" y de su Protocolo de adhesión, es inadmisible y carece de valor alguno ante el derecho internacional. Por tanto, no es cierta la aseveración del profesor y excanciller, Julio Llinares (q.e.p.d.); quien señala que

"La condición dos o Reserva Nunn [...] autoriza a Panamá y a los Estados Unidos de América para celebrar acuerdos militares que permitan el establecimiento de fuerzas armadas estadounidenses o el 
mantenimiento de sitios de defensa de los Estados Unidos en la República de Panamá, después del 31 de diciembre de 1999, sin el consentimiento de los Estados que se adhieran o hubiesen adherido a los objetivos del Tratado de Neutralidad o del régimen de neutralidad establecido en dicho tratado" (Linares, julio, 1983, Tratado Concerniente a la Neutralidad Permanente y al Funcionamiento del Canal de Panamá, 1983, Panamá, página 240).

La aseveración contiene dos falsedades. La Reserva Nunn es inadmisible conforme a la Convención de Viena sobre el derecho de los Tratados, por las razones antes señaladas. Pero aún suponiendo, sin conceder, que tuviera validez, la Reserva Nunn no "autoriza" la celebración de ningún acuerdo sino únicamente consigna un entendimiento según el cual nada en el "Tratado de Neutralidad" impide que se acuerde la presencia militar extranjera; un entendimiento basado, eso sí, en una falacia escandalosa, en una imposibilidad intrínseca.

Tampoco es cierto que Panamá y los Estados Unidos puedan acordar el mantenimiento de sitios de defensa estadounidense, "sin el consentimiento de los Estados que se adhieran o hubiesen adherido a los objetivos del "Tratado de Neutralidad" o del régimen de neutralidad establecido en dicho tratado", porque, como dispone el artículo 41.1 de la Convención de Viena sobre el Derecho de los Tratados,

"Dos o más partes en un tratado multilateral podrán celebrar un acuerdo que tenga por objeto modificar el tratado únicamente en sus relaciones mutuas: [...] b) si tal modificación no está prohibida por el tratado, a condición de que: [...] 1) no afecte al disfrute de los derechos que a las demás partes correspondan en virtud del tratado ni al cumplimiento de sus obligaciones; y II) no se refiera a ninguna 


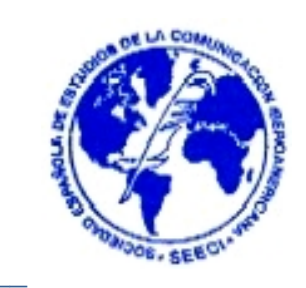

disposición cuya modificación sea incompatible con la consecución efectiva del objeto y del fin del tratado en su conjunto".

En consecuencia, Panamá y los Estados Unidos no pueden celebrar un acuerdo sobre sitios de defensa porque el mismo modificaría el "Tratado de Neutralidad" para todos los signatarios y no sólo entre ambos Estados. Semejante acuerdo violaría el Artículo $V$ del "Tratado de Neutralidad", la ausencia de fuerzas extranjeras y la neutralidad toda, a cuyo goce tienen derecho los signatarios del Protocolo y cuyo mantenimiento constituye una obligación asumida por estos últimos. Tampoco pueden Panamá y los Estados Unidos celebrar dicho acuerdo porque el mismo constituiría la eliminación, más que la modificación, del Artículo V, la cual es incompatible con la consecución efectiva del objeto y del fin del "Tratado de Neutralidad" en su conjunto: la neutralidad permanente.

Conforme al Artículo 41.2 de la Convención de Viena sobre el derecho de los Tratados, Panamá y los Estados Unidos tendrían la obligación de notificar al resto de los signatarios del Protocolo al "Tratado de Neutralidad" su intención de suscribir un acuerdo sobre bases militares:

\section{"[...] las partes interesadas deberán notificar a las demás partes su intención de celebrar el acuerdo y la modificación del tratado que en ese acuerdo se disponga".}

Pero, además, la Reserva Nunn fue incorporada al "Tratado de Neutralidad" por los Estados Unidos después del plebiscito del 23 de octubre de 1977 que lo aprobó.

Dicha Reserva fue aceptada por el gobierno panameño en el instrumento de Canje de Ratificaciones de junio de 1978, pero en vista de que con ello se incurrió en la violación de una norma fundamental del derecho interno panameño, cabe la posibilidad de un alegato sobre vicio del consentimiento, conducente a la nulidad del 
"Tratado de Neutralidad"; porque la reserva Nunn, incluida en el instrumento de Canje de Ratificación, no fue aprobada por el pueblo panameño en plebiscito nacional pese a formar parte de los Tratados del Canal: dicha Reserva contradice radicalmente los acuerdos originales.

Al respecto, como se desprende del Artículo 46.1 de la Convención de Viena sobre el derecho de los Tratados "El hecho de que el consentimiento de un Estado en obligarse por un tratado haya sido manifestado en violación de una disposición de su derecho interno concerniente a la competencia para celebrar tratados, no podrá ser alegado por dicho Estado como vicio de su consentimiento, a menos que esa violación sea manifiesta y afecte a una norma de importancia fundamental de su derecho interno."

La violación del Artículo 274 de la Constitución de la República de Panamá (1972), una norma de importancia fundamental de nuestro derecho interno por razones de todo orden, fue, por tanto, pública, notoria y manifiesta. El artículo 274 de la Constitución de la República de Panamá, 1972, señala lo siguiente:

"Los tratados que celebre el órgano ejecutivo sobre el Canal de esclusas, su zona adyacente y la protección de dicho Canal, lo mismo que para la construcción de un nuevo Canal a nivel del mar o de un tercer juego de esclusas, se someterán a plebiscito nacional".

\section{Protocolo de adhesión al "Tratado de Neutralidad"}

El "Tratado de Neutralidad" contiene normas relativas al régimen de neutralidad permanente, por una parte, y reglas del funcionamiento del Canal, por la otra. El régimen de neutralidad está consignado en los Artículos I, II, IV y V, en tanto que el funcionamiento del Canal es el objeto fundamental del Artículo III. El Artículo VII del 
"Tratado de Neutralidad" lo abrió a la adhesión internacional a través de un Protocolo y designó a la Organización de Estados Americanos como depositaria del mismo. El "Tratado de Neutralidad", bilateral por el origen de su negociación, adquirió carácter multilateral en virtud de dicho artículo. Sin embargo, ninguno de los signatarios del "Tratado de Neutralidad" o del Protocolo al "Tratado de Neutralidad", Panamá y los Estados Unidos, en primer lugar, aparece como "garante" de la neutralidad.

Aparte de Panamá y los Estados Unidos, otros 41 Estados han suscrito dicho Protocolo a partir de 1980. En el Protocolo del "Tratado de Neutralidad", las Partes Contratantes, [Artículo I], "reconocen el régimen de neutralidad permanente y adhieren a sus objetivos"; y acuerdan, [Artículo II], "observar y respetar el régimen de neutralidad". Pero, las Partes Contratantes en el Protocolo únicamente se comprometen a reconocer, a acordar observar, a respetar y a adherir al régimn de neutralidad mas no al "Tratado de Neutralidad" propiamente dicho.

Es decir, se obligan respecto a una parte del "Tratado de Neutralidad", porque conforme al Artículo I
"Las Partes Contratantes, por este medio, reconocen el régimen de neutralidad permanente del Canal establecido por el Tratado Concerniente a la Neutralidad Permanente y al Funcionamiento del Canal de Panamá y adhieren a sus objetivos".

Obsérvese que el mismo título del "Tratado de Neutralidad" se refiere a la neutralidad permanente como algo distinto al funcionamiento del Canal y que el Artículo I del Protocolo al "Tratado de Neutralidad" se refiere al reconocimiento de dicha neutralidad mas no al funcionamiento del Canal. Panamá y los Estados Unidos tienen la obligación de mantener el régimen establecido en el "Tratado de Neutralidad", en tanto que los Estados signatarios del Protocolo sólo tienen el deber de observar y respetar el régimen neutral. En consecuencia, estos Estados se obligan 
a observar, a respetar y a adherir, como parte del régimen neutral, el principio de la desmilitarización, o ausencia de fuerzas extranjeras, consignado en el Artículo V, condición signe qua non del régimen de neutralidad permanente.

\section{Presencia militar extranjera y "Tratado de Neutralidad"}

El "Tratado de Neutralidad" y su Protocolo constituyen un escollo jurídico para un eventual convenio entre Panamá y los Estados Unidos, o entre éstos y otros países, que autorice la presencia de tropas, armas, naves, aeronaves, equipos e instalaciones militares extranjeras después del 31 de diciembre de 1999.

Panamá y los Estados Unidos, más que los demás países, tienen la obligación de evitar el desmoronamiento del régimen de neutralidad: en virtud del Artículo IV del "Tratado de Neutralidad".
"La República de Panamá y los Estados Unidos de América convienen en mantener el régimen establecido en el presente tratado, el cual será mantenido a efecto de que el Canal permanezca permanentemente neutral [...]".

Un Tratado que permita la presencia militar extranjera no es entonces posible, a menos que Panamá y Estados Unidos pretendan violar flagrantemente el "Tratado de Neutralidad" y su Protocolo: ese nuevo Tratado sería violatorio de los Artículos I, II, IV y V del "Tratado de Neutralidad" y de los Artículos I y II de su Protocolo, que sólo consta de tres artículos.

De conformidad con el Artículo 60.2 a) de la Convención de Viena sobre derechos de los Tratados, una violación grave de un tratado multilateral por una o algunas de las partes, facultará: 
"[...] a las otras partes, procediendo por acuerdo unánime, para suspender la aplicación del tratado total o parcialmente o darlo por terminado, sea: I) en las relaciones entre ellas y el Estado autor de la violación o entre todas las partes".

También facultará, artículo 60.2 c) de la Convención de Viena sobre el derecho de los Tratados,

"a cualquier parte, que no sea el Estado autor de la violación, para alegar la violación como causa para suspender la aplicación del Tratado total o parcialmente con respecto a sí misma [...]".

Para los efectos del presente artículo, constituirá una violación grave de un tratado, según el artículo 60.3 b) de la Convención de Viena sobre el derecho de los Tratados, "la violación de una disposición esencial para la consecución del objeto o del fin del tratado."

La violación de los artículos citados del "Tratado de Neutralidad" y de su Protocolo constituiría la violación de varias disposiciones esenciales para la consecución del único objeto de dichos acuerdos, la neutralidad permanente del Canal y, al mismo tiempo, abriría, también, el paso a la suspensión o denuncia del "Tratado de Neutralidad". 